\title{
Pricing Digital Products and Services in Electronic Commerce
}

\author{
Ying Sai \\ Loyola Marymount University \\ E-Mail: ysai@lmu.edu
}

\begin{abstract}
Given its increasing impact on the economy, e-commerce has attracted attentions of scholars from a broad range of disciplines. One of the questions that still remain is: "How to determine prices for digital products and services?" When some products that used to be sold in the regular market with a price tag, and now they are distributed free over the Internet, then, pricing these products becomes a challenging issue. We have proposed a "singing lottery ticket" pricing mechanism that might give the users the incentive to pay a small subscription fee to download the music.
\end{abstract}

Keyword: Pricing, Electronic Commerce, Lottery

\section{INTRODUCTION}

Electronic commerce has made its entry into the main stream of market economy. In the 80's, most companies used Internet as billboard to post general information about themselves, such as office hours, company history, and sales contacts. Start from the early 90's, companies begins to market their products online. Now the electronic commerce has developed into a period far beyond selling products online. It has changes how products are designed, manufactured, distributed and sold.

Personalized products certainly not only limited to PCs and cars, millions of iTunes users have purchased individual songs and compost their own favorite albums; thousands of online gamers have created their cyber characters, furniture, and then, sold them through online auctions. Given its wide impact on the world economy, e-commerce has attracted attentions of scholars from a broad range of disciplines. At a NSF workshop hosted by the Center for Research in Electronic Commerce at University of Texas at Austin, a group of top-notch scientists from many different countries has identified an array of the most crucial research topics of the new economy. One of the topics is how to determine the market price for digital products 
and services that sold through electronic commerce. In a recently published book, scholars (Whinston, Choi, and Stahl, 1990) also acknowledge that it is still an open question: how to determine prices for digital products and services. This important topic is what this research is intended to address.

This paper is organized as follows: Section 2 defines what are digital products and services, and then gives a summary of some of their characteristics that are most relevant to this research. In section 3, we explain the significance of this pricing issue. In section 4, we review some of the economic pricing literature and pricing mechanisms. In section 5, we will discuss some of the pricing mechanisms that might suitable in selling digital products and services. Section 6 concludes this paper with discussion on the implications of this research and future works that might further our understanding in this area.

\section{DIGITAL PRODUCTS AND SERVICES}

What are digital products and services? How can anyone identify them? In what ways are they different than the physical products? These are the questions we will address in this section.

\section{What are digital products and services?}

In a broad sense, any product that is in a digital format can be considered as digital product. We can categorize them in the following way: The first group contains the products that are in digital format, but stored in a physical material and transported as physical product. The second group contains the products that are in digital format and transported to the end user through communication cables or wireless devices. The third group includes services that are represented in digital format and offered through online or wireless connections. This type of services includes travel reservation services, stock trading, banking services and online shopping. In this paper, we focus our attention mainly on these digital products and services that are transmitted through the Internet or wireless connections. Next section is devoted to these common characteristics.

\section{Characteristics of Digital Products and Services}

The purpose of discussing the characteristics of digital products and services is not only for identifying them, but also for understanding the implications these characters may have on their prices and prices setting mechanisms. 
- No loss in quality during duplication

A unique fact about duplication of digital products is that there is no loss in quality during the duplication process. The act of downloading a IRS form does not reduce the quality of the original form.

- Takes negligible storage space

Technology innovations have made unprecedented advances in reducing storage spaces for digital data. Apple Computer's iPod can hold a lifetime's collections of favorite tunes.

- Timely delivery

Almost all the digital services are available on the web 24/7.

- Ease of transferring and processing

Another characteristic of digital products and services is that they can be transferred and processed more accurately, efficiently and at lower cost than manual process. Once the electronic returns are received by IRS could check for errors and irregularities in the returns immediately.

In this section, we have discussed four major characteristics of digital products and services and pointed out some the implications to pricing. In the next section, we will turn our attention to the significance of pricing digital products and services.

\section{THE SIGNIFICANCE OF PRICING DIGITAL PRODUCTS AND SERVICES}

Finding the right pricing mechanism for digital products and services is an important issue. It has major implications in the development of e-commerce. There is more people log on to the Internet than ever before, and new business models and practices are coming to the market everyday. Some of the traditional pricing schemes that have been trusted for decades are no longer suited to requirement of the online business.

In addition to rapid growth and new business practices, another significant change is how content-based digital products are sold. The famous Napster case is a good example to illustrate this point. Even though, in 2001, RIAA made Napster change to fee base services after series of legal battles, but other free music exchange services sprouting out and took Napster's place on the web, continuing the business of providing free music singles to online users. Napster case has demonstrated that pricing digital products is not only an economic issue, it could be a highly controversial issue that challenge the current assumption on the ownership of copy righted products: music, movies and books. 


\section{DIMENSIONS OF PRICING MECHANISMS}

Existing economic literature provides rich and valuable resources that could assist us in search for possible solutions for pricing digital products in e-commerce. In this section, we will first review each major pricing mechanism, and then we will discuss how these pricing mechanisms can be applied in the e-commerce setting.

Cost is identified as one of the major factors in determining price in traditional economic literature (Samuelson and Nordhaus, 2001). This fact holds true not only in economic theories, but there are also empirical evidence supports the view that main influence leading to price changes is a change in the level of cost (Nishimura, 1989). Most discussion of marginal cost pricing take for their basis on the work of Harold Hotelling (1939). Hotelling's system adequately allowed for charging additional fees whenever the demand at marginal cost would exceed the available supply (Ruggles, 1949).

Since the marginal cost in producing the additional copy is so insignificant compare with the fixed cost, if the price were set as equal to marginal price, the total income from such pricing mechanism may not cover the fixed cost. Besides, it is impractical to charge customer few cents for a copy itself. Therefore the concept of marginal cost doesn't provide much clue in determine prices for digital products and services. Is cost always a main factor in determine price? The answer is: “depends.” Some people believe that it is not fair to focus on the cost of raw ingredients alone, because no one would calculate the value of a Picasso based on the cost of the paint.

When the demand is exceed the available resource, economist might suggest that to adopt one of two primary approaches: quality limits and peak load pricing (Schmalensee, 1982). The marginal cost of producing an additional copy of digital product is very small, therefore, it is economically sensible for the seller to mass-produce and reach broader market. A high speed Internet connection is necessary for game-on-demand applications. It is estimated that broadband services will reach 16.6 million homes by 2004 .

Mass-customization was a dream for economists before e-commence takes hold in the economy. In practice, airline industry has used such pricing strategy of years. McAfee (1996) indicated that price/quality discrimination has achieved its only purpose---to separate the low willingness-to-pay consumers from the high willingness-to-pay consumers. In general, economists (Schmalensee, 1982; Schwartz, 1990; Varian, 1985) agree that price differentiation is more efficient than no price differentiation at all. 


\section{MECHANISMS FOR PRICING DIGITAL PRODUCTS AND SERVICES}

We have summarized the characteristics of digital products and services, and reviewed some of the literatures and online practices of price setting strategies. To attract more visitors to the site is of vital importance to the business, various techniques have been used to attract more visitors, for example lowering price, giving free samples, offering grocery coupons or a chance to win vacations. We will discuss how lottery might work for some of the online products, and how mass-customization and demand collection can be implemented on the web

\section{Singing Lottery Tickets}

The popularity of state lotteries in America has grown over the last several decades. In 1986, revenues from all games offered total 12.5 billion dollars to the states, whereas in 1996, revenues from all lottery games toped 34 billion dollars. Besides making money for the states, lottery also was used for some other purpose. For example, in the U.S., lottery has been proposed as an alternative method for allocating communication spectrum (Schmalensee, 1987). Demands on the communication spectrum have increased sharply because of the growth in radio communication services, the large bandwidth now required for transmitting images and motion pictures, and the rapid increases in world population.

In 1980s, the US government allocated cellular communication licenses by lottery (McMillan, 1995; McAfee, 1996). The lotteries succeeded in assigning licenses quickly, but the prospect of the windfall gain attracted 400,000 applicants. Assigning licenses at random is hardly likely to put resources into the hand of the firm that are able to make the best used of them. Therefore, in 1993, Congress decided to switch to auctions for the new mobile communication licenses. In e-commerce, online services providers may use lottery as a price setting strategy, which might be attractive to some of the online users.

Study has shown that lottery tickets, in the value of about a dollar each, have positive effects on raising medical survey response rate in Australia (Kalantar and Talley, 1999; Ward, Boyle, Long, \& Ovadia, 1996). Medical survey is especially hard for obtaining good response rate, since it often contains very personal and sometimes intruding questions. A team of researchers administrated a medical survey to 400 pre-selected populations. Half of the people received lottery tickets along with their questionnaires, and the other half of the population received identical questionnaires but without lottery tickets. Result shown that the group revived lottery tickets had $70 \%$ of the response rate, while the other group has the usual $38 \%$. May be in 
e-commerce, online business can increase the number of visitation by giving out lottery tickets when the customer makes purchase orders.

The music industry, having learned from the experience of Napster, is struggling to reinvent itself for the new era. On one hand, it formed a consortium with consumer electronic companies, to develop new standard for the digital music and devices that plays it. On the other hand, it is trying to develop new pricing schemes that would make file sharing seems unnecessary. But how that music will be delivered and how it will be paid for is still very much in flux, especially if it is delivered online. To use lottery as part of the price-setting scheme seems to be a feasible approach. A music site can charge a small subscription fee for its users and each time the user download a song, he/she would be given a lottery ticket with certain probability to win a large prize. Therefore, the user would not only get a piece of music, but also a lottery ticket. Such combination could be called "singing lottery ticket".

There are potential drawbacks for distributing lottery tickets over the Internet, which related to social and psychological well being of the public health. Lottery is a form of gambling, and there are some major public health issues such as gambling addiction, family dysfunction and gambling by youth need to be addressed. Study has linked new technologies to gambling related problems such as addiction to gambling by video lottery terminals (Korn, 2000; Ladouceur, Vitaro, and Côté, 2001) It is certain that some of these emerging issues need to be further studied to balance risks and benefit of online services and lottery.

An interesting phenomenon on the Internet is that many individuals and organizations offer digital products and services for free. Free doesn't mean there is no value associate with them. These free products or services have great value for someone in need. Many people are willing to contribute their time and effort to these online communities without monetary reward. This phenomenon is certainly welcomed by the million of online users; however it is a puzzle for the economists who used to associate products and services with costs and prices in dollars and cents. One of the most basic concepts of economic is the relationship between supply and demand. Price is the key in balance this relation so scarce resources are used inn an efficient way. However, it is clear that some of the concept need to be redefined on the Internet. When the cost of duplicating a product is almost zero, what are scarce resources? When the distribution between supplier and consumers are not clear, who should pay whom? When Valuable products are distributed with out charge, what are the means of value and price? 


\section{CONCLUSION}

This research was set out to explore the open question that was identified by a group of researcher (Whinston, Choi, \& Stahl, 1990): how to price digital products and services in e-commerce. After the research on this subject, we conclude that there "no one size fit all" answer to this question. When some products that use to be sold in the regular market with a price tag, are now being distributed free over the Internet, then, pricing becomes a challenging issue. We have proposed a "singing lottery ticket" pricing scheme that might give the users the incentive to pay a small subscription fee to download the music. Through this price scheme, we hope to make the free distributing of copyrighted material on online obsolete.

There still are works to be done in the field of pricing digital protects and services. One of them is how one can implement "singing lottery ticket" idea on the Internet without the social and psychological drawback of gambling. E-Commerce is changing rapidly; new communication technologies could affect the pricing strategies. Another approach would be to initiate a joint effort from other related disciplines to design the pricing mechanism.

\section{REFERENCES}

Hotelling, H. (1939). The Relation of Prices to Marginal Cost in an Optimum System. Econometrica, 7(2), 151-155.

Hunter, P. (2002). DRM: Whose Rights are They Anyway? Computer Fraud \& Security, 2002 (2), 14-15.

Kalantar, J. S., \& Talley, N. J. (1999). The effects of lottery incentive and length of questionnaire on health survey response rates: a randomized study. Journal of Clinical Epidemiology, 52(11), 1117-1122.

Korn, D. A. (2000). Expansion of gambling in Canada: implications for health and social policy. Canadian Medical Association Journal, 163(1), 61-64.

Ladouceur, R., Vitaro, F., \& Côté, M. A. (2001). Parents' attitudes, knowledge, and behavior toward youth gambling: a five-year follow-up. Journal of Gambling Studies, 17(2), 101-116.

McAfee, R. P., \& McMillan, J. (1996). Analyzing the Airwaves Auction. The Journal of Economic Perspectives, 10(1), 159-175.

McMillan, J. (1995). Why auction the spectrum? Telecommunications Policy, 19(3), 191-199.

Nishimura, K. G. (1989). Customer Markets and Price Sensitivity. Economica, New Series, 56(222), 187-198. 
Ruggles, N. (1949-1950). Recent Development in the Theory of Marginal Cost Pricing. The Review of Economic Studies, 17(2), 107-126.

Samuelson, P. A., \& Nordhaus, W. D. (2001). Economics. New York NY: McGraw-Hill Irwin.

Schmalensee, R. (1987). Collusion versus Differential Efficiency: Testing Alternative Hypotheses. Journal of Industrial Economics, 35(4), 399-425.

Schmalensee, R. (1982). Product Differentiation Advantages of Pioneering Brands. The American Economic Review, 72(3), 349-365.

Schwartz, M. (1990). Third-Degree Price Discrimination and Output: Generalizing a Welfare Result. The American Economic Review, 80(5), 1259-1262.

Varian, H. R. (1985). Price Discrimination and Social Welfare. The American Economic Review, 75(4), 870-875.

Ward, J., Boyle, C., Long, D., \& Ovadia, C. (1996). Patient surveys in general practice: a randomized trial of an instant lottery ticket to increase return rate. Australian Family Physician, 1, 19-20.

Whinston, Choi and Stahl, (1990). The Economics of Electronic Commerce. New York NY: Mc Millian Technical Publishing. 